\title{
Erratum: Music structure determines heart rate variability of singers
}

\section{Björn Vickhoff ${ }^{1}$, Helge Malmgren ${ }^{2}$, Rickard Åström ${ }^{3}$, Gunnar F. Nyberg ${ }^{4}$, Seth-Reino Ekström ${ }^{5}$, Mathias Engwall ${ }^{6}$, Johan Snygg ${ }^{7}$, Michael Nilsson ${ }^{1,8}$ and Rebecka Jörnsten ${ }^{9}$}

${ }^{1}$ Center for Brain Repair and Rehabilitation, Institute of Neuroscience and Physiology, Sahlgrenska Academy, University of Gothenburg, Gothenburg, Sweden

2 Department of Philosophy, Linguistics and Theory of Science, University of Gothenburg, Gothenburg, Sweden

${ }^{3}$ Professional Musician and Composer, Torslanda, Sweden

${ }^{4}$ Department of Clinical Physiology, Sahlgrenska University Hospital, Gothenburg, Sweden

${ }^{5}$ Cantor, Kalvshult, Sweden

${ }^{6}$ Department of Cultural Sciences, University of Gothenburg, Gothenburg, Sweden

${ }^{7}$ Department of Anaesthesia and Intensive Care, Sahlgrenska University Hospital, Gothenburg, Sweden

${ }^{8}$ Hunter Medical Research Institute, University of Newcastle, Newcastle, NSW, Australia

${ }^{9}$ Department of Mathematical Sciences, University of Gothenburg and Chalmers University of Technology, Gothenburg, Sweden

${ }^{*}$ Correspondence: bjorn.vickhoff@neuro.gu.se

\section{Edited by:}

Edward W. Large, Florida Atlantic University, USA

Keywords: choral singing, heart rate variability, respiratory sinus arrhythmia, frequency analysis, autonomic nervous syste

\section{A commentary on}

Music structure determines heart rate variability of singers.

Vickhoff, B., Malmgren, H., Åström, R., Nyberg, G., Ekström, S.-R.,
Engwall, M., et al. (2013). Front. Psychol. 4:334. doi: 10.3389/fpsyg.2013. 00334

\section{ERRATUM}

Figures 4, 5, 10, 13 in the article "Music structure determines heart rate variability of singers" by Vickhoff et al. published in Frontiers in Psychology, 09 July 2013 (doi: 10.3389/fpsyg.2013.00334) contain a labeling error: The singing task tags "Hymn" and "Mantra" appear in the wrong order.

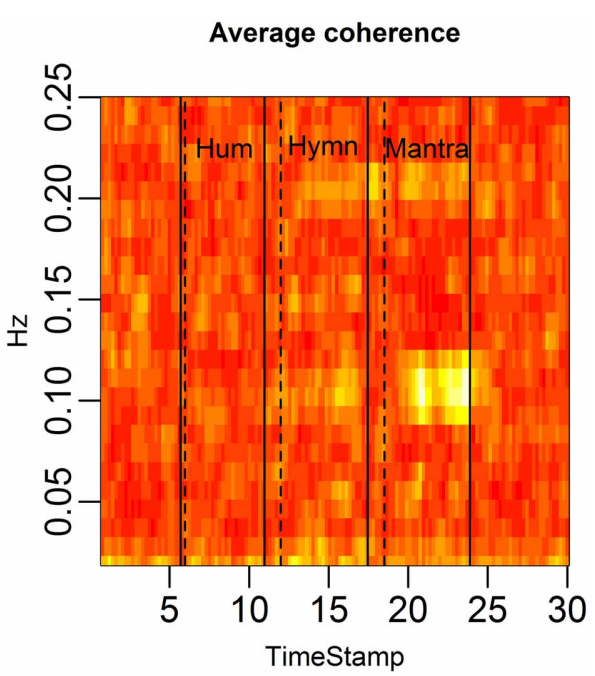

FIGURE 4 | HRV between-subject coherence. Each column of the figure represents the average coherence across pairs of subjects for a certain time window. Each row represents a frequency in $\mathrm{Hz}$. The coherence is computed in rolling windows of length $96 \mathrm{~s}$, step size $12 \mathrm{~s}$. The coherence summarizes the co-variation (correlation) of two subjects per frequency. In the figure, brighter colors represent higher coherence. Coherence is clearly higher during the mantra than during any other condition $(0.1 \mathrm{~Hz})$. Coherence is also higher during the hymn than during humming and baseline.

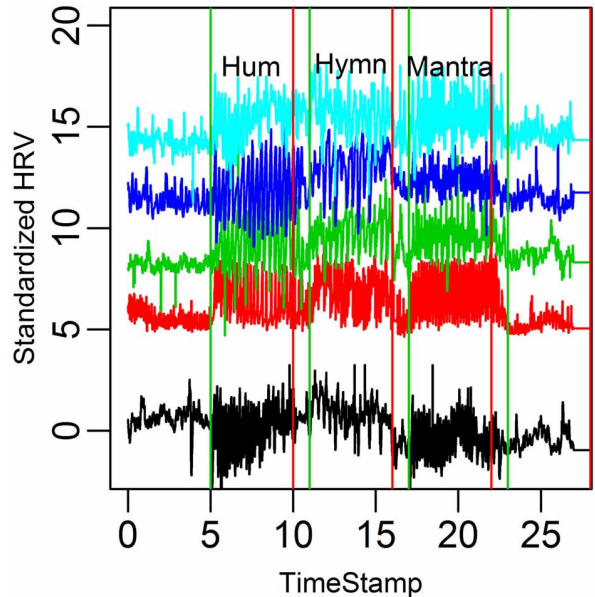

FIGURE 5 | HR graphs for the five subjects in the case study over the entire time domain. 


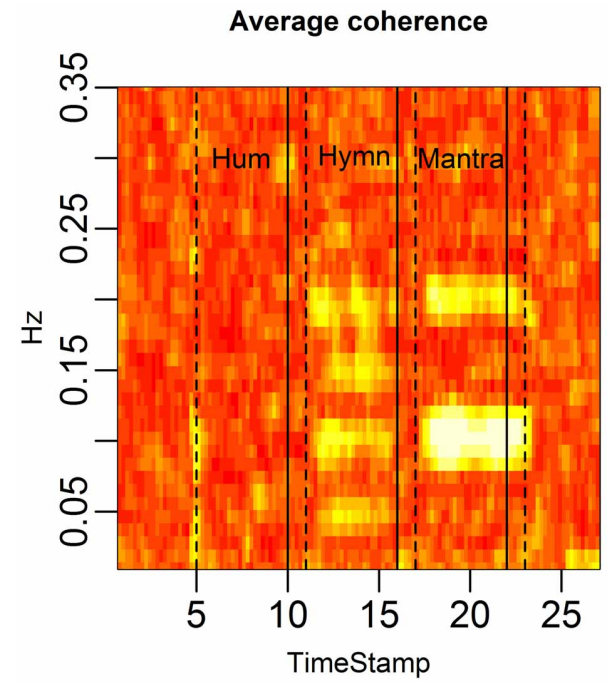

FIGURE $10 \mid$ HRV coherence for the case study. Each column of the figure represents the average coherence across pairs of subjects for a certain time window. Each row represents a frequency in $\mathrm{Hz}$. The coherence was computed in rolling windows of length $96 \mathrm{~s}$, step size $12 \mathrm{~s}$ (cf. Figure 4). Coherence is clearly high during the mantra (at $0.1 \mathrm{~Hz}$ and at the harmonic frequency $0.2 \mathrm{~Hz}$ ). There is also high coherence during the hymn (at $0.05,0.1$, and $0.2 \mathrm{~Hz}$, and the harmonic $0.15 \mathrm{~Hz}$.
The correct order of the singing task labels is: "Hum" (5-10 min segment), "Hymn" (11-16 min segment) and finally "Mantra" (17-22 min segment).

Figures with correct labeling appear in this Erratum.

Received: 22 July 2013; accepted: 18 August 2013; published online: 05 September 2013.
Citation: Vickhoff B, Malmgren H, Åström R, Nyberg GF, Ekström S-R, Engwall M, Snygg J, Nilsson $M$ and Jörnsten R (2013) Erratum: Music structure determines heart rate variability of singers. Front. Psychol. 4:599. doi: 10.3389/fpsyg.2013.00599

This article was submitted to Auditory Cognitive Neuroscience, a section of the journal Frontiers in Psychology.

Copyright (C) 2013 Vickhoff, Malmgren, Aström, Nyberg, Ekström, Engwall, Snygg, Nilsson and Jörnsten.

\section{Coherence Respiration-HR}

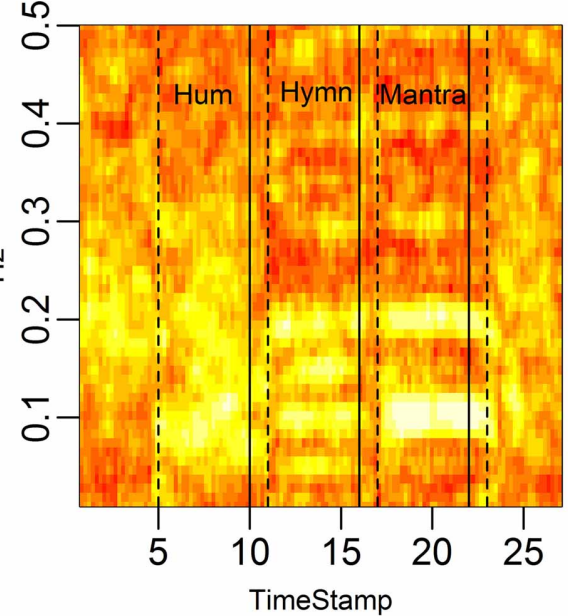

FIGURE 13 | RSA is defined as the coherence between respiration depth and HR. We depict the average RSA across subjects in rolling windows of length $96 \mathrm{~s}$, stepped by $12 \mathrm{~s}$. Each column represents the coherence at different frequencies for a given time point and each row the coherence for a particular frequency across time. RSA is markedly high during the mantra (at 0.1 and the $0.2 \mathrm{~Hz}$ harmonic) as well as during the hymn (at $0.05,0.1$, and $0.2 \mathrm{~Hz}$ ). RSA is also high during the hum segment, albeit not a common dominant frequency as expected since respiration frequency is highly individual during humming.
This is an open-access article distributed under the terms of the Creative Commons Attribution License (CC BY). The use, distribution or reproduction in other forums is permitted, provided the original author(s) or licensor are credited and that the original publication in this journal is cited, in accordance with accepted academic practice. No use, distribution or reproduction is permitted which does not comply with these terms. 